\title{
GERENCIALISMO E AVALIAÇÃO DE POLÍTICAS DE FORMAÇÃO DOCENTE: A FORÇA DOS INDICADORES SOCIALMENTE REFERENCIADOS ${ }^{1}$
}

\author{
GERENCIALISMO Y EVALUACIÓN DE POLÍTICAS DE FORMACIÓN \\ DOCENTE: LA FUERZA DE LOS INDICADORES SOCIALMENTE \\ REFERENCIADOS
}

\section{MANAGERIALISM AND EVALUATION OF TEACHER TRAINING POLICIES: THE STRENGTH OF SOCIALLY REFERRED INDICATORS}

\author{
Maria Inês BOMFIM ${ }^{2}$ \\ Valeria Morgana GOULART ${ }^{3}$
}

RESUMO: O trabalho apresenta, de forma abrangente, as opções teóricometodológicas de uma experiência alternativa de avaliação na área de formação docente com o uso de metodologias e características distintas das propostas hegemônicas desenvolvidas no âmbito do Estado brasileiro, no atual momento. Busca-se refletir sobre desafios da investigação no campo das políticas públicas, problematizando possibilidades de ruptura com a ideologia gerencialista, que promove rigidez metodológica, por meio de indicadores de avaliação tecnicistas e pragmáticos. O estudo questiona as possibilidades de se fugir dos indicadores de produtividade em avaliação de políticas públicas de formação docente, sem perder o necessário rigor na avaliação.

PALAVRAS-CHAVE: Avaliação de políticas públicas. Formação docente. Gerencialismo.

RESUMEN: El trabajo presenta, de manera amplia, las opciones teóricometodológicas de una experiencia alternativa de evaluación en el área de formación docente con el uso de metodologías y características distintas de las propuestas hegemónicas desarrolladas en el ámbito del Estado brasileño, en el actual momento. Se busca reflexionar acerca de los desafios de la investigación en el campo de las políticas públicas, problematizando posibilidades de ruptura con la ideología gerencialista, que promueve rigidez metodológica, por medio de indicadores de evaluación tecnicistas y pragmáticos. El estudio cuestiona las posibilidades de huir de los indicadores de la productividad en evaluación de políticas públicas de formación docente, sin perder lo necesario rigor en la evaluación.

1 Uma primeira versão do presente artigo foi apresentada no $6^{\circ}$ Congresso Ibero-Americano em Investigação Qualitativa (CIAIQ), realizado em Salamanca (Espanha), nos dias 12, 13 e 14 de julho de 2017.

${ }^{2}$ Universidade Federal Fluminense (UFF), Rio de Janeiro - RJ - Brasil. Docente na Faculdade de Educação. E-mail: mariaines.uff@gmail.com.

${ }^{3}$ Fundação Oswaldo Cruz (FIOCRUZ). Enfermeira e especialista em Gestão e Economia em Saúde. Tecnologista em Saúde da Vice-Presidência de Ensino, Informação e Comunicação da FIOCRUZ. Email: valeria.morgana@fiotec.fiocruz.br. 
PALABRAS CLAVE: Evaluación de políticas públicas. Formación docente. Gerencialismo.

ABSTRACT: This paper presents, in a comprehensive way, the theoretical and methodological options of an alternative evaluation experience in the area of teacher training with the use of methodologies and characteristics distinct from the hegemonic proposals developed within the scope of the Brazilian State, now. It seeks to reflect on research challenges in the field of public policies, problematizing possibilities of rupture with the managerialism ideology, which promotes methodological rigidity, through technical and pragmatic evaluation indicators. The study questions the possibilities of escaping productivity indicators in the evaluation of public policies of teacher education, without losing the necessary rigor in the evaluation.

KEYWORDS: Evaluation of Public Policies. Teacher training. Managerialism.

\section{Introdução}

Nas últimas décadas, os pilares da avaliação, em geral, passaram por mudanças importantes. À avaliação foi conferida uma natureza política, ou seja: a avaliação é afetada por forças políticas e, ao mesmo tempo, é capaz de promover efeitos políticos (HOUSE, 1992; AFONSO, 2009).

No contexto da Reforma de Estado de cunho neoliberal, promovida no país na década de 1990, a avaliação de políticas públicas ganhou centralidade como instrumento de gestão, em busca de um novo perfil de eficiência e qualidade no setor público. Particularmente no campo da educação, esse perfil vincula-se à criação de um ethos competitivo, com o uso de modelos da gestão privada no espaço público, por meio de uma cultura gerencialista, com efeitos importantes para a avaliação. “[...] a competição entre pares e a remuneração por produtividade, tão comuns no setor produtivo, tornaram-se mascotes da política educacional [...]” (SHIROMA, 2003, p. 65).

Newman e Clarke (2012), analisando o caso do Reino Unido, nas décadas de 1980 e 1990, compreendem o gerencialismo como formação cultural e conjunto de ideologias e práticas que compõem a base do novo acordo político, em resposta ao que era compreendido como crise econômica e política.

O gerencialismo como ideologia era essencial para o processo de reforma no Reino Unido porque traduzia um ethos de negócios do setor privado no Estado e no setor público. Ocorre que, mesmo onde os serviços públicos não foram totalmente privatizados (e muitos permaneceram no setor público), era exigido que tivessem um desempenho como se estivessem em um mercado competitivo. Era 
exigido que se tornassem semelhantes a negócios e este ethos era visto como personificado na figura do gerente (em oposição ao político, ao profissional ou ao administrador). Isto introduziu novas lógicas de tomada de decisão que privilegiavam economia e eficiência acima de outros valores públicos (NEWMAN; CLARKE, 2012, p. 358).

Os autores ressaltam, ainda, tendo por base a própria realidade brasileira no que concerne às conquistas populares no campo do direito à saúde no mesmo período, que não é possível estabelecer comparações lineares entre as formas pelas quais o gerencialismo é incorporado nas diferentes regiões. Se o gerencialismo, como ideologia, era essencial para o processo de reforma das décadas de 1980 e 1990, no Reino Unido e em outros países europeus, porque traduzia um ethos de negócios do setor privado para o âmbito do Estado, defende-se, neste trabalho, que a ideologia do gerencialismo vem sendo também essencial ao processo de reformas empreendido, hoje, no Brasil.

Sem desprezar a existência de tensões e conflitos na luta pela hegemonia na definição do sentido e dos desenhos de políticas de avaliação, Lima (2012) observa, como tendência dos últimos anos, a subordinação da investigação a uma razão técnica e instrumental, com um certo pendor pragmatista e utilitário. $\mathrm{Na}$ contramão dessa tendência, a definição de propostas de avaliação, no âmbito do Estado, com indicadores socialmente referenciados e pertinentes ao objeto de investigação, que não se configurem como amarras, mas guias, é um dos desafios da atualidade. Diante disso, duas questões moveram as reflexões aqui apresentadas: é possível fugir da ideologia gerencialista e de indicadores de produtividade em avaliação? Como escapar da rigidez metodológica, pragmatista, sem perder o rigor na avaliação de processos de formação docente?

O presente trabalho integra os estudos realizados no âmbito do grupo de pesquisa Trabalho e Formação Docente em Educação Profissional, da Faculdade de Educação da Universidade Federal Fluminense (UFF). Apresenta, de forma ampla, as opções teórico-metodológicas de uma experiência alternativa de avaliação com o uso de metodologias mistas e características distintas das propostas hegemônicas desenvolvidas no âmbito do Estado, no atual momento. Busca-se, assim, refletir sobre desafios da investigação socialmente referenciada no campo das políticas públicas, problematizando, no atual contexto, as possibilidades de ruptura com a ideologia gerencialista, que promove rigidez metodológica, por meio de indicadores tecnicistas e pragmáticos. 
A proposta formativa, alvo da alternativa de avaliação aqui apresentada, é o Curso de Formação Docente em Educação Profissional Técnica na Área da Saúde, produzido pela Escola Nacional de Saúde Pública Sergio Arouca (ENSP), da Fundação Oswaldo Cruz (FIOCRUZ), instituição do Ministério da Saúde do Brasil, desenvolvido até 2012, em várias unidades da federação, no âmbito das políticas de fortalecimento do Sistema Único de Saúde-SUS. A formação, em nível de especialização, era destinada a profissionais que já atuavam em escolas de educação profissional públicas, privadas e filantrópicas. Eram, portanto, alunos-docentes, sem formação pedagógica, graduados nas diferentes subáreas da saúde (Medicina, Enfermagem, Odontologia etc.).

O Curso buscava caminhos alternativos às propostas que enfatizam, apenas, as técnicas de ensinar e foi realizado de forma semipresencial, com carga horária total de 440 horas. Promovido de forma descentralizada, com o apoio de universidades parceiras, especialmente públicas, a formação adotou a história das lutas sociais por saúde no Brasil como eixo de sustentação da estrutura curricular, de forma a subsidiar a análise da complexa realidade do setor e do processo histórico de defesa da saúde pública.

A experiência privilegiava a reflexão e a crítica sobre o trabalho docente realizado nas escolas de educação profissional que formam trabalhadores para o Sistema Único de Saúde-SUS, reconhecendo-se que as efetivas mudanças na realidade em saúde e em educação demandam, também, transformações no modelo social.

Partindo das contribuições de Pistrak (2000) sobre a relação teoria-prática, o Curso procurava superar as desarticulações e fragmentações disciplinares, com a adoção de uma estrutura curricular sustentada em complexos temáticos. O complexo temático, vale esclarecer, não é um fim em si mesmo, nem um método. É um meio gerador de ações, em resposta a problemas concretos da prática social, visto que a educação não se limita a interpretar o mundo, mas a desenvolver práticas transformadoras do real.

[...] É preciso estudar os fenômenos em suas relações, sua ação e dinâmica recíprocas, é preciso demonstrar que os fenômenos que estão acontecendo na realidade atual são simplesmente parte de um processo inerente ao desenvolvimento histórico-geral [...] assim, a questão do ensino unificado, da concentração do ensino por complexos, torna-se uma questão candente; a questão do método que agora se coloca não é simplesmente de uma assimilação melhor e mais completa destes ou daqueles estudos; trata-se de uma questão que se relaciona com a essência do problema pedagógico, com o conhecimento dos fenômenos atuais e suas relações e dinâmicas recíprocas [...] (PISTRAK, 2000, p. 36). 
A avaliação teve como finalidade apreender, de forma contextualizada, as possibilidades e os limites dessa formação, bem como a sua contribuição para a transformação da realidade, na medida em que a proposta discutia as condições essenciais em que as práticas de saúde e de educação eram realizadas, assumindo um papel político explícito (SAVIANI, 2000). Não era, assim, uma atividade de monitoramento, nem uma avaliação padronizada da proficiência dos participantes.

Para o processo formativo e também para o processo de avaliação, alguns princípios se destacaram:

- O entendimento da saúde e da educação como produções sociais impõe o reconhecimento de uma categoria essencial à compreensão da realidade: a totalidade.

- Superar visões unilaterais contribui para compreender a dinâmica de cada momento histórico, em cada sociedade e, ainda, por que os homens de cada tempo determinam as circunstâncias e, ao mesmo tempo, são determinados por elas.

- O trabalho em saúde e em educação é influenciado pela dinâmica política e social, variando conforme a correlação de forças e a consequente ação do Estado, e a presença de distintos atores que atuam nessas áreas.

- O processo de trabalho em saúde é de natureza interdisciplinar. No entanto, a crescente racionalização das práticas de saúde tem se caracterizado pela decomposição dos atos e intervenções realizados por vários trabalhadores diferentes, resultando em um conjunto fragmentado de atos individuais com base em mecanismos instituídos de dominação de relações assimétricas de poder entre as várias corporações profissionais.

\section{Avaliação de processos de formação docente: o sentido das opções teórico- metodológicas}

As práticas em educação e em saúde são, em grande medida, produzidas e cerceadas por um conjunto de estruturas, forças e valores presentes e atuantes em cada realidade, síntese, portanto, de várias determinações. Como práticas sociais, saúde e educação expressam concepções de mundo e podem contribuir para manter ou mudar a realidade. Diante disso, refletir sobre a potencialidade de uma proposta formativa que busca contribuir para mudanças foi, certamente, o primeiro desafio da avaliação.

Com apoio em Saviani (2000, p. 65), defende-se que a potencialidade da proposta formativa analisada estaria vinculada às suas efetivas possibilidades de proporcionar aos participantes do Curso: uma aguda consciência da realidade em que 
atuavam; uma adequada fundamentação teórica que lhes permitisse uma ação coerente e uma satisfatória instrumentalização técnica que lhes possibilitasse uma ação eficaz.

Entre as questões gerais que serviram de guia para a avaliação, destacam-se as seguintes: o Curso contribuiu para que o docente compreendesse as múltiplas dimensões envolvidas nos problemas da saúde e da educação profissional dos trabalhadores em saúde? Estimulou o aluno-docente a tomar a prática social em saúde como ponto de partida e ponto de chegada do fazer pedagógico? A problematizar a realidade social como elemento-chave da relação entre a saúde e o processo de adoecimento? A explicitar o compromisso docente com a saúde como direito de todos, com as necessidades sociais de saúde e com os usuários sujeitos de direitos? Tais questões estão relacionadas às circunstâncias socialmente condicionadas, como mencionado. Resultam de determinada visão no real, nele encontrando suas razões e seus objetivos (MINAYO, 2005).

A avaliação, em razão do seu complexo objeto, optou pelo uso de metodologias mistas, com ênfase na investigação qualitativa, evitando-se reforçar dicotomias entre modelos quantitativos e qualitativos. A abordagem quantitativa buscava identificar padrões comuns a universos distintos, como, por exemplo, as condições concretas de trabalho do conjunto de participantes, marcadas pelos processos de desregulamentação dos vínculos profissionais, de fragilidade contratual e de intensificação das atividades, tendo em vista as alterações promovidas pela atual fase do desenvolvimento capitalista. Já a abordagem qualitativa, por sua vez, trouxe como contribuição um contato estreito e direto com a realidade investigada e com os sujeitos envolvidos.

Tendo em vista o objeto, os objetivos e a opção por metodologias mistas, foram selecionados como instrumentos e técnicas: o questionário, a realização de grupos focais e a análise dos Trabalhos de Conclusão de Curso (TCC), estes últimos, obrigatórios em cursos de pós-graduação lato sensu. A observação da prática docente em escolas configurou-se como aporte metodológico complementar bastante rico.

No caso da avaliação quantitativa, a amostra probabilística definida garantiu percentuais acima dos padrões amostrais geralmente utilizados no Brasil (cerca de 20\%). A partir dessa amostra, foram definidas subamostras aleatórias visando à seleção de Trabalhos de Conclusão de Curso (TCC) e de alunos-docentes para a composição de grupos focais representativos de todas as instituições parceiras na realização do Curso. No total, foram realizados 34 grupos focais, com participação de 222 alunos-docentes. Além disso, foram analisados 267 Trabalhos de Conclusão de Curso-TCC e, de forma 
complementar, procedeu-se à observação da prática pedagógica docente em oito escolas de educação profissional, o que caracteriza a ênfase conferida à avaliação qualitativa. A opção por grandes amostras também na investigação qualitativa foi intencional, em virtude da complexidade do objeto.

O enfoque da análise de conteúdo proposto por Bardin (1979), com algumas atualizações, serviu de base para a organização dos dados e para o mapeamento dos resultados da investigação qualitativa. Os dados qualitativos e quantitativos foram analisados de forma contextualizada, buscando-se uma concepção relacional da realidade (BOURDIEU; WACQUANT, 2012).

De modo a assegurar a consistência da avaliação de natureza qualitativa, em bases teórico-metodológicas sólidas e, tendo em vista o objeto da investigação, definiram-se como requisitos de seleção dos pesquisadores a formação em Ciências Humanas ou Sociais, em nível de mestrado ou doutorado, e a experiência anterior na realização de grupos focais. Participaram da investigação 12 pesquisadores e um estatístico, responsável pela elaboração do plano amostral. $\mathrm{Na}$ fase inicial, foram discutidos, em profundidade, o objeto, pressupostos teóricos e possibilidades metodológicas, sendo planejado o desenho da avaliação de forma coletiva.

Uma das primeiras atividades foi o estudo meticuloso, pela equipe de avaliação, do Projeto do Curso, de seus objetivos, de sua matriz teórica e metodológica, decidindose pelo aprofundamento em torno das categorias trabalho, trabalho docente e trabalho em saúde e, ainda, pela construção de indicadores de avaliação que norteassem a elaboração de todos os instrumentos utilizados: questionários, roteiros de grupos focais e de observação e de análise de trabalhos de conclusão.

Como Minayo (2005), compreende-se que indicadores são parâmetros qualitativamente elaborados, capazes de detalhar se os objetivos de uma proposta foram adequadamente alcançados, embora não sejam capazes de dar conta da totalidade do real. Por isso, mesmo, quando são muito potentes, assinalam, apenas, determinadas tendências. Não oferecem certeza quanto aos resultados de uma ação ou de um processo.

$\mathrm{Na}$ avaliação, foram considerados, também, aspectos relacionados às possibilidades do Curso: carga horária da proposta, condições concretas de vida e trabalho dos alunos-docentes, bem como características da formação em nível superior recebida, muitas vezes tecnicista, nas quais saúde e educação foram vistas como aspectos isolados do todo social, sendo a saúde pública conteúdo acessório. Em razão 
disso, é preciso ressalvar os limites desta ou de qualquer outra proposta formativa voltada para o significado social da ação educativa no âmbito da saúde pública, que traz conhecimentos de campos desconhecidos, pelos alunos-docentes, como os da História, da Filosofia, da Sociologia e da Educação.

\title{
Avaliação: a força de indicadores socialmente referenciados
}

Analisando os atuais referenciais de avaliação na Inglaterra e, em Portugal, Lima (2012) mostra uma realidade também conhecida no Brasil.

\begin{abstract}
As dimensões burocráticas do exercício da avaliação externa têm-se revelado evidentes, seja pela aplicação uniforme e estandardizada dos critérios, pela manifesta falta de conhecimento do contexto sociocultural e acadêmico por parte da maioria dos avaliadores, seja pela tônica colocada nos indicadores de quantidade e de status, mais típicos das ciências e tecnologias (LIMA, 2012, p. 73)
\end{abstract}

De fato, é pouco provável que, nos dias atuais, fosse possível garantir a necessária autonomia para a definição de indicadores de avaliação socialmente referenciados também no Brasil. Improvável, também, que uma formação como a descrita fosse levada adiante. Ball (2001), traz elementos para compreender os impedimentos à realização de tais propostas, na atualidade. Os novos paradigmas de gestão pública, adverte o autor, incluem uma atenção mais focada nos resultados em termos de eficiência, eficácia e qualidade dos serviços, flexibilidade para criação de alternativas de baixo custo e criação de objetivos voltados à produtividade.

Lima (2012), entretanto, considera que, apesar de estamos sendo confrontados com vários problemas, não é possível desprezar as potencialidades do campo da educação. Nos espaços de disputa de sentidos característicos das práticas sociais, a proposta de avaliação em tela teve plenas condições de realização no período compreendido entre 2010 a 2012. Aos pesquisadores, não foi imposta nenhuma restrição, nem de caráter ideológico, nem financeiro em razão da abrangência da avaliação proposta, nem de prazos. Os indicadores de avaliação expressavam um conjunto de pressupostos teóricos socialmente referenciados e procuraram traduzir valores, compromissos e atitudes de grande amplitude que representam uma determinada forma de atuar na docência em educação profissional na área da saúde. Nessa perspectiva, compreendemos que a formação docente em saúde não é neutra, assim como a avaliação também não o é. 
Defende-se, ainda, que faz parte do cuidado metodológico da avaliação o rigor e não a rigidez, especialmente quando a natureza do que se pretende avaliar é tão complexa. Tentativas anteriores de avaliação, com base exclusivamente nas percepções dos alunos sobre o Curso mostraram-se insuficientes. O fato de o Curso ser gratuito e conferir ao participante o título de especialista na docência em educação profissional na área de saúde, em nível de especialização, de certa forma contaminava as apreciações. Diante disso, criar parâmetros que definissem, com mais clareza, o que se queria observar mostrou-se uma necessidade. Vale esclarecer que a ênfase conferida à esta opção em nada se aproxima ao que Wacquant (2005) denomina de metodologismo, ou seja, a inclinação a separar a reflexão sobre os métodos de seu uso real, cultivando o método por si mesmo.

Os indicadores de avaliação do Curso foram definidos com base no perfil do aluno que seria formado: um professor da área da saúde que associe uma visão crítica e ampla da sociedade às competências de sua área de atuação; que atue, de forma interdisciplinar, nas lutas pelo atendimento integral e de qualidade ao usuário do Sistema Único de Saúde (SUS) e concorra para a transformação da realidade, com autonomia intelectual, social e ética.

São apresentados, a seguir, indicadores construídos a partir de dois dos aspectos do perfil docente acima indicado: Visão crítica e ampla da sociedade associada às competências técnicas de sua área de atuação e Atuação que evidencie autonomia intelectual, social e ética (FIOCRUZ/ENSP, 2010). Foram detalhadas, também, as respectivas questões orientadoras. Tais indicadores e suas questões orientadoras poderiam ser ampliados, caso a realidade assim demandasse, o que se mostrou necessário ao longo da avaliação.

\section{Visão crítica e ampla da sociedade associada às competências técnicas de sua área de atuação}

\section{Indicadores:}

- Explicitação, no fazer pedagógico, de múltiplas dimensões (conceitual/científica/ técnica, histórica, econômica, política e cultural) envolvidas nos problemas da saúde e da educação profissional em saúde.

- Enfase na prática social em saúde como ponto de partida e ponto de chegada do fazer pedagógico. 
- Problematização da realidade social como elemento-chave da relação entre saúde e o processo de adoecimento.

- Explicitação, no Trabalho de Conclusão do Curso (TCC) e na prática pedagógica, da centralidade do compromisso em relação à saúde como direito e dos alunos como sujeitos que produzem cultura.

- Explicitação, no TCC, de posicionamento crítico em relação aos limites e possibilidades da prática docente em saúde, considerando os condicionantes da realidade sócio - histórica.

\section{Questões orientadoras}

- Que dimensões estão presentes nos objetivos e nos conteúdos da disciplina sob a responsabilidade do docente? Qual é a ênfase? Qual a participação do docente nesta elaboração?

- O docente interroga, questiona a realidade em saúde, no âmbito do SUS, suas contradições e possibilidades, articulando-a com a totalidade social?

- O fazer pedagógico contempla a produção histórica do conhecimento inerente à sua disciplina, bem como o processo histórico de construção dos termos legais e da realidade do SUS?

- O aluno docente explicita seu conhecimento acerca dos condicionantes sóciohistóricos do trabalho em saúde e em educação e encaminha em sua ação pedagógica possibilidades de superação deles?

- O TCC expressa articulação das questões da saúde e da educação com os condicionantes da realidade sócio- histórica?

- A ação pedagógica (aspectos teóricos e práticos) tem como ponto de partida e de chegada as necessidades concretas de saúde da população?

\section{Atuação que evidencie autonomia intelectual, social e ética}

\section{Indicadores}

- Explicitação, no TCC (particularmente na definição dos objetivos do trabalho e na abordagem do tema) de uma postura crítica em relação aos valores hegemônicos na "sociedade de mercado" que desconsideram os seres humanos como medida de todas as coisas. 
- Atuação profissional e cidadã que denote o reconhecimento da importância da ação coletiva para a promoção de mudanças de caráter ético-político na auto formação permanente e na formação de seus alunos.

- Atuação pedagógica (âmbito teórico-prático) propiciadora de vivência, por parte dos alunos, da condição de sujeitos portadores de direitos e produtores de cultura.

- Atuação pedagógica centrada no reconhecimento da importância de que os alunos construam qualificação técnica coletiva necessária à atuação de qualidade socialmente referenciada no atendimento aos usuários do SUS.

- Atuação pedagógica que possibilite, aos alunos, a apreensão consistente dos conhecimentos fundamentais à análise da vida social, em particular no que concerne à área da saúde.

\section{Questões orientadoras}

- Nos diferentes momentos de sua ação pedagógica o docente estabelece, permanentemente, a articulação entre a teoria e a prática?

- Que dimensões teórico-práticas estão presentes no Trabalho de Conclusão do Curso - TCC do docente? Qual é a ênfase? Evidencia-se a articulação teoria prática?

- O aluno docente analisa criticamente a proposta curricular do Curso em que atua, identificando se o mesmo é elaborado com base na tradição de ensino fragmentado e parcial da área da educação profissional em saúde? Discute o assunto com outros docentes que atuam no mesmo espaço educativo?

- $\mathrm{O}$ aluno docente sente-se seguro para indicar alternativas à proposta curricular existente? Evidencia compreender as implicações ético-políticas de seu trabalho como professor?

- O aluno docente preocupa-se em articular sua disciplina às outras desenvolvidas por outros docentes? Participa de reuniões/encontros para discussão de alternativas de integração?

- O aluno docente, em sua prática pedagógica, analisa criticamente com os alunostrabalhadores a divisão técnica existente nas equipes de saúde?

- O aluno docente evidencia em sua prática pedagógica compromisso com a superação de formação estreita, com ênfase nos procedimentos, destituída dos 
fundamentos teórico-práticos que permitem compreender a totalidade do cuidado em saúde?

Embora não seja propósito deste estudo apresentar os resultados da investigação realizada, indicam-se alguns dos aspectos centrais observados em todas as etapas da avaliação. Nos grupos focais, em especial, foram destacadas a preocupação com direitos sociais não assegurados e a insuficiente qualidade dos serviços oferecidos pelo SUS. Igualmente, foram frequentes as manifestações de compromisso com os usuários como sujeitos de direitos. Frustração, angústia e indignação foram sentimentos relatados por alunos-docentes diante de situações do trabalho nos serviços de saúde e nas escolas de educação profissional, evidenciando tensões entre as potencialidades transformadoras e as limitações existentes (BOMFIM; GOULART; OLIVEIRA, 2014).

\section{Considerações finais}

Nossos estudos vêm mostrando que, no Brasil, a ideologia gerencialista avançou de maneira acelerada e profunda nos últimos anos. Uma de suas marcas é a chamada austeridade no âmbito do Estado. Austeridade, avaliam Newman e Clarke (2012) é apenas o projeto político e governamental mais recente para tentar articular novos acordos. Em razão disso, questiona-se: é possível fugir da ideologia gerencialista e de indicadores de produtividade em avaliação de políticas públicas? Como escapar da rigidez metodológica, pragmatista, sem perder o rigor na avaliação de processos de formação docente?

Em relação à primeira questão, considera-se que, na atualidade, as propostas de avaliação de políticas sociais hegemônicas mostram, pelo seu caráter frequentemente pragmatista e descontextualizado, que os espaços para realização de investigações pautadas pelo pensamento crítico estão cerceados. A autonomia democrática das instituições que realizam investigações está restrita, não apenas pelos limites impostos pelos ajustes fiscais, como pela hegemonia da ideologia gerencialista. Tal ideologia, que referencia as propostas de avaliação, não é privilégio nosso, como mencionado. $\mathrm{O}$ distanciamento das instituições de pesquisa europeias da cultura acadêmica de tradição crítica, capaz de desafiar o Estado e os poderes públicos, já foi observado no continente europeu há mais tempo.

A esse respeito, Lima (2012) revela que organizações internacionais de tipos diversos como, por exemplo, A União Europeia, a Unesco, a OCDE e o Banco Mundial 
vêm produzindo e divulgando conhecimento sobre educação, modelos e resultados de avaliações, as chamadas boas práticas, tudo em sintonia com a busca de produtividade característica da ideologia gerencialista. Nesses casos, as metodologias exclusivamente quantitativas são consideradas mais ágeis e potentes para medir, de forma objetiva, a magnitude dos fenômenos, o que acaba por definir um status de maior prestígio à elas, com reflexos na produção acadêmica e na definição das fontes de financiamento pelas agências de fomento públicas.

Não há tempo nem recursos financeiros para propostas que não ofereçam respostas rápidas, ainda que superficiais. Se é imperioso reconhecer que as condições do quadro político atual não estimulam a liberdade de crítica, apostar na avaliação de políticas públicas com indicadores socialmente referenciados, como momento privilegiado de luta pela democratização, parece um rico caminho. É preciso considerar que a saúde, a educação e também a avaliação são alvo de disputa permanente de sentidos, inclusive no âmbito do Estado.

Em relação à segunda questão, destaca-se que os obstáculos impostos à investigação em bases socialmente referenciadas, em particular na área de políticas públicas de formação de professores, não são nem secundários, nem desprezíveis, principalmente quando se tem em mente a necessidade de assegurar bases teóricometodológicas sólidas nos processos avaliativos. Em virtude do fetiche em torno da técnica, expressão de um neotecnicismo, considera-se oportuno indicar novos/velhos desafios a serem enfrentados.

Um deles diz respeito à definição com rigor, mas não com rigidez, do objeto da investigação, como uma das apostas ainda necessárias. Se, de um lado, prevalecem as avaliações com ênfase quantitativa, como mencionado, de outro, a ideia de que tudo é possível em investigação qualitativa tem limitado a sua potencialidade. Não há nessa aposta, isto é, na defesa do rigor, mas não da rigidez, uma valorização positivista da supremacia da investigação quantitativa, em detrimento da qualitativa, nem de uma oposição entre teoria e metodologia, tradição tão presente na investigação, de forma geral.

Os indicadores e as questões orientadoras da proposta apresentada neste trabalho tiveram como origem opções teóricas e metodológicas que constituíam o próprio objeto de investigação. Eram aspectos estruturantes da avaliação, numa perspectiva crítica, nas brechas encontradas dentro da cultura política de tradição autoritária do Estado brasileiro. Investiu-se no processo coletivo de construção, o que tomou tempo 
significativo da avaliação, a fim de se evitar o que Bourdieu \& Wacquant (2012) denominam de "audácia sem rigor e rigor sem imaginação". Tal construção não era um procedimento técnico, apenas. Constitui-se como momento privilegiado da investigação, tendo em vista a necessidade de se evitar um laissez faire epistemológico, já que a construção de um indicador ou, a inclusão de cada novo item nos instrumentos, demandam opções teóricas, conscientes ou não (BOURDIEU; WACQUANT, 2012).

Outro desafio a ser enfrentado é a tendência de separar a reflexão sobre os métodos de seu uso real, cultivando o método por ele mesmo, reduzindo o problema da construção teórica do objeto à manipulação técnica dos indicadores e dos instrumentos. A teoria, vale lembrar, é o conhecimento que orienta não só a coleta de dados, mas a sua própria análise.

De fato, na experiência de avaliação relatada, a produção de um vasto número de instrumentos, bem como o tempo destinado à sua elaboração, discussão e crítica, indicava um risco permanente àquilo que Wacquant (2005) denomina de metodologismo, que desafia a investigação porque estimula a consolidação de uma miopia científica. De outro lado, se o endeusamento da técnica produz um formalismo árido, seu desprezo pode levar a especulações estéreis (MINAYO, 2005). Em outras palavras, se o metodologismo é sempre uma ameaça, a teoria também não pode estar separada do trabalho de investigação que a alimenta.

\section{REFERÊNCIAS}

AFONSO, A. J. G. Avaliação educacional: regulação e emancipação: para uma sociologia das políticas avaliativas contemporâneas. São Paulo: Cortez, 2009.

BALL, S. J. Diretrizes políticas globais e relações políticas locais em educação. Currículo sem Fronteiras, v.1, n.2, pp.99-116, Jul/Dez 2001.

BARDIN, L. Análise de conteúdo. Lisboa: Edições 70, 1979.

BOMFIM, M. I.; GOULART, V. M. P.; OLIVEIRA, L. Z. Formação docente na área da saúde: avaliação, questões e tensões. Interface, Botucatu, 18(51):749-58, 2014.

BOURDIEU, P.; WACQAUNT, L. Una invitación a la sociología reflexiva. Buenos Aires: Siglo Argentino Editores, 2012.

FIOCRUZ/ENSP. Indicadores de qualidade social da avaliação da Formação Docente. BOMFIM, M. I.; RUMMERT, S. Rio de Janeiro, RJ: Fundação Oswaldo Cruz; Escola Nacional de Saúde Pública Sergio Arouca, 2010. 
HOUSE, E. R. Tendencias en evaluation. Revista de Educacion. Ministerio de Educación, Cultura y Desporte, 299, 43-55, 1992.

LIMA, L. C. Aprender para ganhar, conhecer para competir: sobre a subordinação na sociedade da aprendizagem. São Paulo: Cortez, 2012.

MINAYO, Maria Cecília (Org.) Avaliação por triangulação de métodos: abordagens de programas sociais. Rio de Janeiro: Editora FIOCRUZ, 2005.

NEWMAN, J.; CLARKE, J. Gerencialismo. Educ. Real., Porto Alegre, v. 37, n. 2, p. 353-381, maio/ago. 2012.

PISTRAK, M. M. Fundamentos da escola do trabalho. São Paulo: Expressão Popular, 2000.

SAVIANI, D. Educação: do senso comum à consciência filosófica. Campinas: Autores Associados, 2000.

SHIROMA, E. O. Política de Profissionalização Aprimoramento ou Desintelectualização do Professor? Intermeio: revista do Mestrado em Educação, Campo Grande, MS, v. 9, n. 17, p. 64-83, 2003.

WACQUANT, L. Hacia uma praxeologia social: la estrutura y la lógica de la sociologia de Bourdieu. In: BOURDIEU, P.; WACQAUNT, L. Una invitación a la sociología reflexiva. Buenos Aires: Siglo Argentino Editor, 2012.

\section{Como citar este artigo:}

BONFIM, Maria Inês Bonfim.; GOULART, Valéria Morgana. Gerencialismo e avaliação de políticas de formação docente: a força dos indicadores socialmente referenciados. Temas em Educ. e Saúde, Araraquara, v.13, n.2, p. 286-300, jul./dez. 2017. Disponível em: <https://doi.org/10.26673/rtes.v13.n2.jul-dez.2017.10677>. EISSN: 2526-3471.

Submetido em: 30/04/2017

Aprovado em: 20/08/2017 